\title{
Restoration of the Elementary School "Johann Heinrich Pestalozzi"-Skopje
}

\author{
Dimitar Papasterevski, Aleksandar Radevski \\ Faculty of Architecture, Ss Cyril and Methodius University, bul. Partizanski odredi 24, Skopje, Republic of Macedonia
}

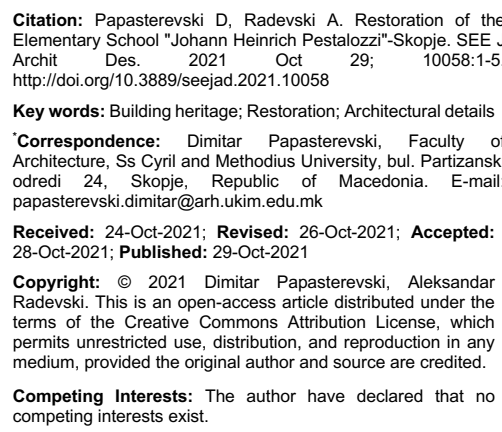

\section{Abstract}

The post-earthquake rebuilding of Skopje provided valuable examples of modernist architecture that deserve to be included in the category of a protected building heritage. A prominent instance is the elementary schoo named after the famous Swiss educator and pedagogue "Johann Heinrich Pestalozzi", the first example in this area that introduces the practical application of deeply thought-out methods of integral education promoted by him in the early 19th century. Many contemporary architects have incorporated the efficient use of this educational concept, including the renowned Swiss architect Alfred Roth, creating a unique sample of a school that includes specific geographic and regional features (climatic, seismic, cultural - aesthetic). In terms of properties, the building contains originality, rarity, and aesthetic-artistic value. With reference to other criteria, it also includes the value of authentic preservation, which is in crisis without adoption of adequate and prompt protection and restoration measures.

In respect of protecting the school from further destruction, the Swiss Embassy in Skopje made an official request for a study and design documents for the school reconstruction by detecting all critical issues developed and executed by the expert team from the Faculty of Architecture in Skopje. This paper, which is based on the results of the research, conducted by us as a part of the group, aims to elaborate the methodological approach of the analyses contained in the study, which, as a pre-design procedure, provided a solid base for developing design documents.

A significant component of the study that needs to be emphasized was the use of computer technology throughout the work process, using parametric insertion of structural and other elements of the building's architecture into a 3D model. This approach allowed the generation of architectural details across any part of the facility in an exact form, which proved extremely useful through the process of constructing the design documents.

\section{Introduction}

The Elementary School" Johann Heinrich Pestalozzi" is an exceptional illustration of the modernist architecture of a school building built in the Republic of Macedonia and in the wider region and therefore can be considered an architectural masterpiece [1]. Its construction has indicated the end of the traditional concepts of school buildings, which were generally designed according to a template concept. Furthermore, it implied the practical application of deeply thoughtful methods of holistic education promoted by the renowned Swiss pedagogue and educational reformer Johann Heinrich Pestalozzi in the early 19th century. The practical application of the aforementioned educational concept was also joined by progressive architects, including the famous Swiss architect Alfred Roth [Alfred Roth (19031998 ) is a Swiss architect educated in Karl Mozers and Le Corbusiers atelier, widely known as a specialist for school buildings], the designer of the school" Johann Heinrich Pestalozzi" who created a unique sample of a school adapted to the modern educational system and specific regional characteristics. Considering the fact that the building contains the cultural and historical heritage values of the 20th century, it is entitled to a careful restoration to its original authentic state and incorporation in the modern society of the 21st century from a complete educational, cultural and aesthetic aspect [2]. A team comprised of eminent experts from the Faculty of Architecture was established with an objective to initially elaborate a reconstruction study of 
the Elementary School "Johann Heinrich Pestalozzi"Skopje (I) as a pre-design procedure, and prepare design documents (Construction Documents) for the school reconstruction (II) (The team consisted of: Prof. Ph.D. Tihomir Stojkov; Ass. prof. Ph.D. Dimitar Papasterevski; Prof. Ph.D Vladimir Simovski; Prof. Ph.D. Mihail Tokarev; Ass. prof. Ph.D Ana Ivanovska; Ass. prof. Ph.D Mihajlo Zinovski).

\section{Review to the Reconstruction Study of the Elementary School "J. H. Pestalozzi' - Skopje}

The School Reconstruction Study was conceptualized as a scientific, research study, which, as a pre-design experience and method, has proven to be extremely useful in generating relevant information essential in the elaboration of design documents.

\section{Building \\ Documentation and Evaluation of the}

Documentation of the building is the fundamental milestone of the study elaboration influencing the research in the design chronology, elaboration of design documents and construction process. The expert team was presented with a unique opportunity and challenge in the analysis of the available design documents (Final Design with architectural details) mainly developed by the author Alfred Roth, as well as an insight into some of the working architectural details formulated by the Construction Company "Beton" Skopje. Furthermore, much of the design documents archived in the Skopje City Archives were utilized as a solid basis for the actual evaluation of the problem situation, and a possibility of a comparative analysis of the designedbuilt-preserved relations. The construction of the school building "J. H. Pestalozzi" took place in the course of 1967 and 1968, and it was commissioned in 1969. The result was a promotion of high quality and unique school space. Over the past 40 years, the school has proven its functionality in fully meeting the high teaching standards of an eight-year elementary school. In addition to its architectural and functional properties, the building is also referenced for its characteristic seismically designed structural system foundation insulation applied to the classroom tract. The construction of the school building was considered a pioneering endeavor in the field of seismic protection at the time it was built.

\section{Architectural and Aesthetic Features}

The Elementary School functional solution develops and refines the educational concept set up by the Bauhaus school building in Dessau, Germany (1926), designed by Walter Gropius. A pavilion system for the allocation of basic functional units was applied: multi-purpose Aula with administrative and teacher's room (A), a pavilion with classrooms on $\mathrm{G}+2$ (B and $C$ ), a laboratory wing on $\mathrm{G}+1$ (D) and a gym with accompanying facilities $(E)$, which implies rational construction and use of the facility (Figure 1).
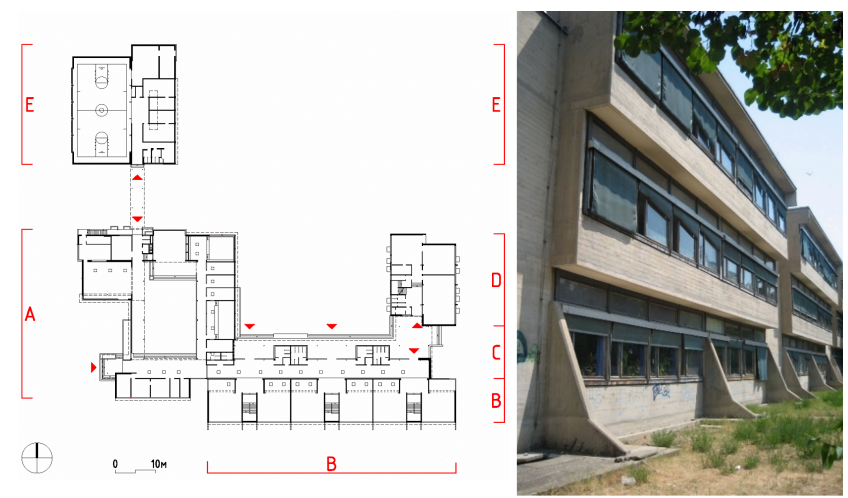

Figure 1: Ground floor plan of Elementary School "Johann Heinrich Pestalozzi" - Skopje and tract with classroom

The main entrance is on the west side of the building with an access to the vestibule and the spacious and expansive multi-purpose Aula with a stage which, rises above all surrounding areas with its double-pitched roof, allowing the indirect illumination of a basilica. The Aula is the focal point, around which is a distribution of management offices, a small school infirmary, teachers' lounge, and parents meeting room, a library and a dining room with a kitchen. Above the kitchen, there is a caretaker's apartment accessible by external stairs. The main volume form on the south side of the ensemble is the ground floor classroom pavilion with two floors. This pavilion has a rhythmic division $1+2+2+1$ in the classrooms formation that allows a staircase for vertical communication between each two classrooms. Each upper classroom level moves horizontally to the south and is cantilevered above the lower level, providing additional zenith light on the north side, concurrently providing sun protection on the south side, shade in the form of horizontal stripes from the cantilever above. The small laboratory pavilion is located on the east side of the ensemble distributed on the ground floor and basement, while the small library is situated on the second floor. The dome of the gym, along with dressing rooms, rises above the northwest corner accessible through the open porch of the Aula.

The architectural expression of the building is a synthesis of the functionalism and constructivism of mid-20th-century modernist architecture, derived from its architectural, functional and constructive design. The classroom pavilion is the main volume form that resembles a street sequence of traditional town houses in this region. The comprehensive spatial-volume structure of the ensemble has a dynamic asymmetrical composition comprised of separate relatively symmetrical spatial units, such as the classroom pavilion and to some extent the schoolyard (Figure 2). The definition of the façade's envelope has been derived from the neo-brutalism of modernist 
architecture, typical for the 1960s.

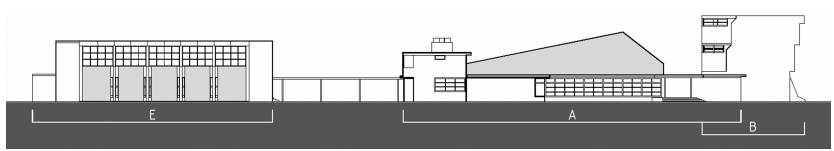

Figure 2: West silhouette - Dinamic composition of the school pavilions: A-Aula; B-Classrooms; E-Gym

\section{Evaluation and Protection}

The starting point in the evaluation of the Elementary school "J. H. Pestalozzi" as a building containing significant cultural-historical heritage values of 20th century is the thorough preceding analysis of the functional, structural and artistic features. The building incorporates a complex of general and specific evaluation criteria regarding: -Architectural values deriving from the specific functional, formative and constructive design; -Authentic preservation, which is in danger without adoption of appropriate protection and restoration measures and initiatives; -Documented value for the development of modernist architecture in the region and beyond; -A sense of curiosity about the overall architectural-structural ensemble.

With reference to the aforementioned value components, the school has been classified as a cultural-historical heritage in the second category containing elements of first category. In conformity with the international conventions and recommendations, a second level of protection is provided for culturalhistorical heritage in the second category, focusing primarily on maintaining the original authenticity of the building.

\section{building \\ Assessment of the current condition of the}

On-site inspection revealed three critical issues within the building as follows: 1. Flat trafficable and non-trafficable roof terraces; 2 . Façade's envelope (reinforced concrete canvas, wall openings - windows, inclined glass surfaces, wall coverings); 3 . Floors and floor structures (in the Aula and the gym).

The general conclusion after the inspection was that the building as a whole has retained its architectural and functional features. However, the poor maintenance of some vital parts such as roof structure, fanlights, rainwater drainage through horizontal and vertical drains (gutters, sheet flashing, dilatations, lightning rod installations, etc.), caused a serious damage. Another alarming issue was the dilapidation of applied materials and damages caused by the rainwater penetration. The domes and the inclined fanlights above the classrooms on the north side were in a severe critical condition, as well as all the wooden windows. Damage was additionally observed to a part of the reinforced concrete canvas throughout the entire building. A leakage of the roof structure caused a permanent damage of the floors in the gym. The inspection revealed unprofessional partial interventions on the flat non-trafficable roof terraces in the dilatation areas as well as in all areas where rainwater leakage 'appeared', (Figure 3).

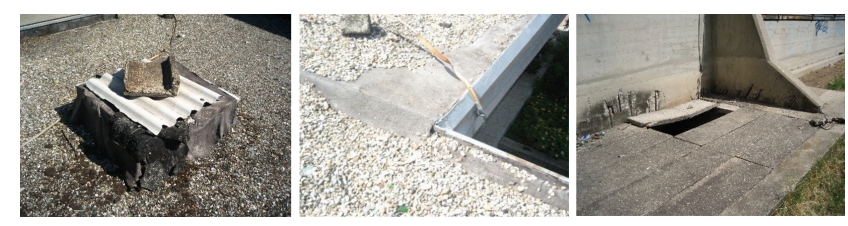

Figure 3: Damage of roof segments and façade's concrete walls

Moreover, there was a critical damage on the gym and Aula envelope constructed from asbestoscement slabs as well as on part of the sheet flashing with the dilatations around the Aula. Most of the gutters on the flat non-trafficable roof terraces were permanently damaged or inoperable, which also caused serious damage to the waterproofing due to rinsing of the protective gravel layer [3].

Elaboration of Design Documents for Reconstruction of the Reconstruction of the Elementary School "J. H. Pestalozzi' - Skopje

Premised on the synthesized results of the research, the expert team has elaborated design documents and provided the Final Design and Construction Design. The most significant component of this segment was the elaboration of the applied methodology in the development of the design documents for the reconstruction of the elementary school "J. H. Pestalozzi", supported by the presentation of some segments of the graphic representations. The systematized selection of specific architectural details as a crucial element in the development of the design documents has been created by defining fragments as spatially functional units of the building. The main approach in the resolution of the key architectural problems has been executed through the research and presentation of architectural details, using the method of subsequent and inverse relation with other graphic representations. This legitimizes the need to expand the range of architectural drawings to a new graphic dimension-distinctive detailed plans and detailed sections. It further allows an easy transposition of architectural details into characteristic plans and vertical sections through the 'detailed-plans and 'detailed-sections' in order to achieve maximum precision and coordination of all parts of the design. In order to facilitate the implementation of solutions to all referred issues, the school building has been divided into five basic sections (see ground floor plan Figure 1).

Furthermore, the implementation of crossreferences to indicate architectural details through various graphic representations allows for easy tracking and "reading" of the design. The explicated methodology has been entirely implemented in the elaboration of the design documents for the school reconstruction (Figure 4). 


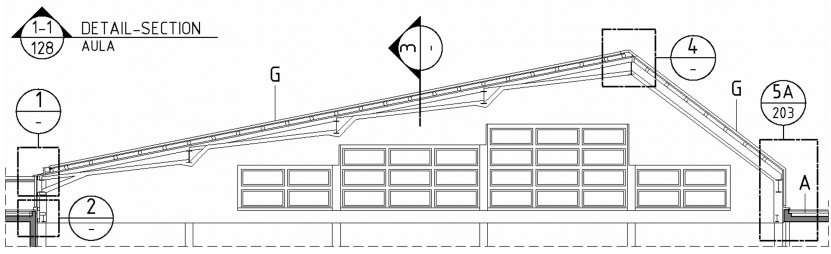

Figure 4: Detail-Section of Aula $M=1: 200$

The available design documents assisted the building's precise digitalization in a 3D model with all its elements using CAD software. The software features to generate sections across the entire building have facilitated the process of further developing numerous architectural details. Taking the scope of the action into consideration, this paper will elaborate only a part of the planned activities presented through the graphic representations in the design documents [4].

\section{Roof - roofing structures}

In connection with the constant poor condition of the roofing and waterproofing, a complete set of new architectural details has been developed for all the critical positions. A comprehensive reconstruction has been proposed for the flat non-trafficable roof terraces, which implies the process of extracting all layers up to the finishing floor structures or subfloors. The process of reconstruction further implies cleaning and remediation of all horizontal and vertical gutters, restoration of perimeter sheet flashing, restoration and remediation of dilatations, and protection of the vertical soil pipes from the toilets appearing on the flat nontrafficable roof terraces. The reconstruction covers the roof pitch of the Aula and the gym with complete replacement of the roofing material after the examination of the existing subfloors and particularly the thermal insulation (Figure 5).

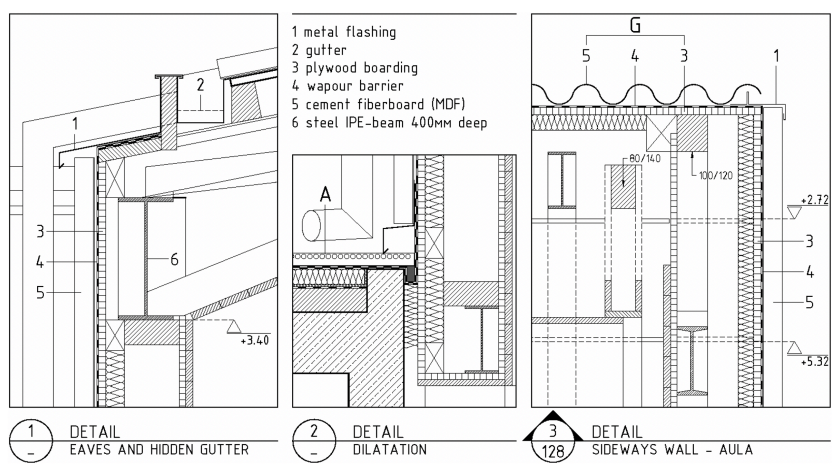

Figure 5: Typical architectural details of roof covering-Detail Section of Aula $1-1, M=1: 20$

The method of generating an architectural drawing-from architectural detail to final design, as a consequential graphic presentation through the development of architectural details, detailed-plans and detailed-sections can be elaborated upon the reconstruction issues on the Aula roof structure.

The subsequent part tackles the detailed section of the entrance porch (Figure 6) and the classroom segment at the level of architectural detail (Figure 7).

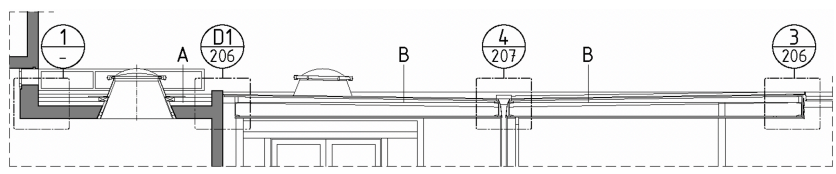

Figure 6: Detail-Section entrance proch classroom, $M=1: 100$

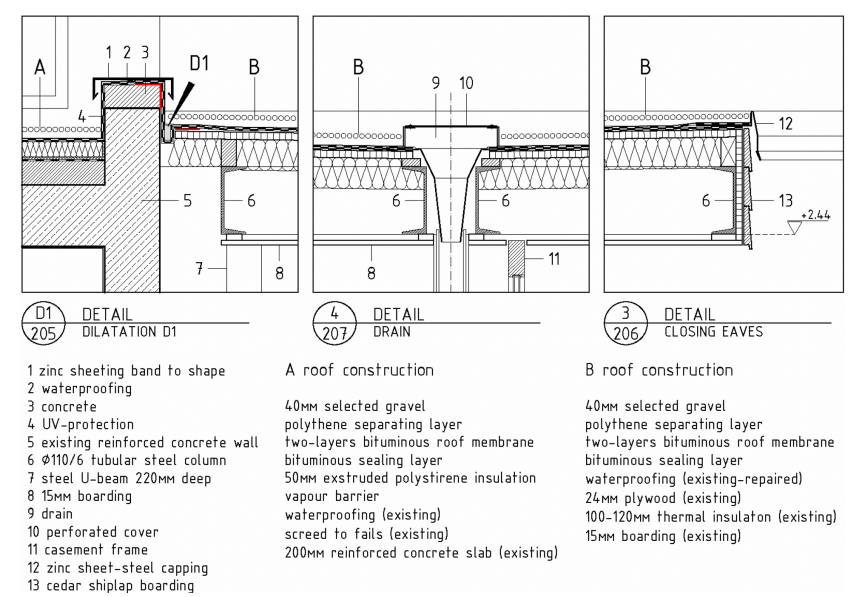

Figure 7: Typical architectural details-Entrance Proch Classroom, $M=1: 20$

\section{Inclined Fanlights}

The inclined fanlights over the northern parts of the classrooms have endured severe visible damage due to dilapidation throughout the years. The research proposes a complete replacement with 24 pieces of new, similar, two-layer polycarbonate, translucent, UV protected glass panes with approximate dimensions of $900 \mathrm{~mm} \times 320 \mathrm{~mm}$, that can be installed upon the existing frame with potential replacement of the casing and sealing materials.

\section{Windows)}

Façade's Envelope (Exterior Walls,

The façade's envelope is comprised of two basic types of construction materials: reinforced concrete canvas as natural concrete as well as partial application of vertically mounted corrugated asbestoscement slabs (Aula and gym). The gravest issue of the façade's envelope is the corrugated asbestos-cement slabs Salonite or Eternit. In compliance with our current regulations and environmental standards, the application of these materials is not permitted and would inevitably obligate their complete and immediate replacement with similar, environmentally friendly material (fibercement boards or similar tiles (Figure 8)). 


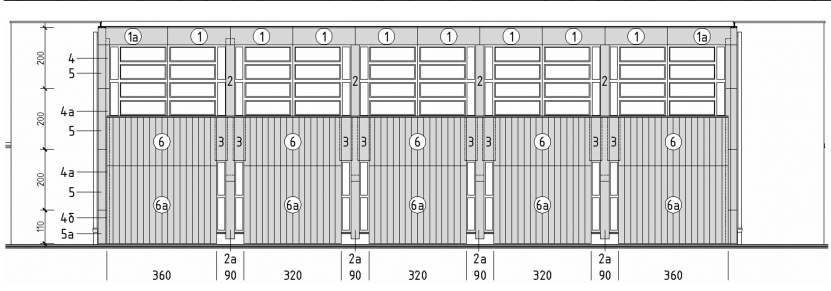

Figure 8: Detail of west elevation-Gym, specification of fibercement boards on façade's envelope

\section{Conclusions}

The period of post-earthquake reconstruction of the city of Skopje was distinguished with the construction of a number of buildings throughout the city containing the idea of modernism, functionalism and brutalism. A vast part of them has undergone a series of unprofessional interventions in the past, which threaten their authenticity in spite of the fact that they remain the city's true representatives of modernist architecture created in the second half of the 20th century. With reference to its distinctive functional, structural and aesthetic concept, in accordance with the UIA Declaration 2000 (International Union of Architects) and the 2005 UNESCO Charter, the building of the elementary school 'J. H. Pestalozzi' can be evaluated as a cultural and historical heritage of the $20^{\text {th }}$ century. The study proposes an initiative for such a process and furthermore provides the basic elements for initiation of the official procedure in obtaining the treatment and the status this architectural masterpiece properly deserves.

\section{References}

1. Denslagen, W.F., and Donald Gardner. 2009. Romantic Modernism: Nostalgia in the World of Conservation. Amstredam: Amstredam University Press.

2. Hoffman, Hans. 2000. "Active Euthanasia: Ten Years of Rehabilitation Work in Eastern Germany." Detail Review of Architecture, no. 7 (Oct-Nov): 1178-1184.

3. Simovski Vladimir. System for modification and lowering of the seismic and other dynamic forces and isolation of the vibrations. Ph. D dissertation (unpublished), Skopje, 1985.

4. Stratton, Michael, ed. 1997. Structure and Style: Conserving Twentieth Centery Buildings. $1^{\text {st }}$ ed. London; New York: E\&FN Spon 